\title{
Academic Library- State Library Agency Relationships: The Pennsylvania Needs Assessment
}

\section{Charles T. Townley, Charles R. Peguese and Kenneth G. Rohm, Jr.}

Relationships between academic libraries and state library agencies are increasingly important components of multitype cooperation. This study assesses the needs of Pennsylvania's academic libraries. Results from a mailed survey identify a number of unmet needs that can be addressed by the state library's Office of Resource Sharing and Academic Libraries. These include: advocacy of academic library needs; linked system protocols; telecommunications; and new technologies. Focus groups composed of selected academic librarians have discussed these unmet needs in some detail, confirming their validity and suggesting how the state library might address them. Both the process and the product of this study may be useful in other states where stronger relationships between state library agencies and academic libraries are desired.

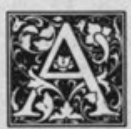
cademic libraries and state library agencies are increasingly interdependent. Academic libraries look to state library agencies to coordinate needs that cross traditional, type-of-library boundaries. State library agencies regard academic libraries as important participants in information access and delivery. The purpose of this study is to assess the needs of academic libraries in Pennsylvania that can be addressed by the State Library of Pennsylvania's Office of Resource Sharing and Academic Libraries. The methodology and results may interest other states that desire stronger relationships between academic libraries and state library agencies.

\section{EMERGING RELATIONSHIPS}

Not so long ago relationships between academic libraries and state library agencies were very limited. State libraries usu-

Charles T. Townley is Division Head, Library and Instructional Services, at Pennsylvania State University, Middletown, Pennsylvania 17057. Charles R. Peguese is Coordinator, Office of Resource Sharing and Academic Libraries, State Library of Pennsylvania, Harrisburg, Pennsylvania 17105. Kenneth G. Rohm is a graduate assistant at Pennsylvania State University. Thanks are extended to The Pennsylvania State University for approving the sabbatical leave that supported this research in part. Thanks are also extended to the State Library of Pennsylvania for providing office support for this project. Opinions expressed do not necessarily represent the policy of the State Library of Pennsylvania. 
ally focused on services to state government, public library development and, in some cases, school library services. ${ }^{1}$ Academic libraries, when they looked beyond their campuses, tended to relate to bibliographic organizations such as the Center for Research Libraries or regional union catalogs. ${ }^{2}$ Occasional consultation might occur on limited topics such as interlibrary loan guidelines. But relationships were, for the most part, left fallow.

Changes in the environment are encouraging academic libraries and state library agencies to develop stronger working relationships. ${ }^{3}$ Academic libraries want to take advantage of new technologies, economies of scale, and resource sharing that can often be approached on a state or regional basis. ${ }^{4}$ State library agencies want to encourage the effective use of all library resources in their respective states. ${ }^{5}$

Title III, Interlibrary Cooperation, of the Library Services and Construction Act (LSCA) has been the catalyst for developing relationships between academic libraries and state library agencies in many states. Added in July 1966, Title III has provided state library agencies with federal funds to encourage cooperation among libraries of all types. As the result of projects funded by LSCA-III, academic libraries and state library agencies in many states have forged relationships to meet their respective needs. ${ }^{6}$ In many states, statutes have been passed, amended, or interpreted to permit state library agencies to work directly with academic libraries. Academic libraries and state library agencies work together to address issues of mutual concern. Much of this work is accomplished through direct grants to consortia and libraries for specific activities. Other work is accomplished by committees, boards, or the staffs of the state agency and participating academic libraries. Relationships are expanding in scope, making them increasingly important components in the environments of both institutions.

Library literature provides three recent proposals for strengthening relationships between academic libraries and state library agencies. ${ }^{8}$ Mitchell proposes improving library services throughout North
Carolina by expanding cooperation among libraries of all types, with a special emphasis on academic libraries. The New Jersey document calls for developing a liaison office in the State Department of Higher Education and full academic library participation in networking. The Montana State Library has recently involved academic libraries in a multitype pilot project to test the feasibility of a statewide union catalog. This study is intended to contribute an empirical base to the literature to assist others in achieving more benefits from emerging relationships between academic libraries and state library agencies.

\section{"With the funding of LSCA-III, the State Library of Pennsylvania began making grants for projects involving academic libraries."}

\section{RELATIONSHIPS IN PENNSYLVANIA}

The experience of Pennsylvania is one example of how relationships have developed between academic libraries and state library agencies. With the funding of LSCA-III, the State Library of Pennsylvania began making grants for projects involving academic libraries. By 1975 , a clear mutual interest in fostering resource sharing was addressed when the state library began using LSCA-III funds to encourage more than fifty academic libraries to enter their holdings into the OCLC database. In 1972 , the state library subsidized the operations of the Interlibrary Delivery Service, a statewide, multitype courier service, created in 1969 with an LSCA-III grant to the Associated College Libraries of Central Pennsylvania.

Concurrently, the state library included academic libraries in a series of studies and directories to enhance resource sharing throughout the commonwealth. Academic libraries were included in the Directory of Pennsylvania Library Resources prepared under contract by the Drexel University Graduate School of Library 
Science in $1972 .^{9}$ Academic libraries were included in federally funded planning documents such as the Pennsylvania Library Master Plan Committee Report of 1974 and Bibliographic Access in Pennsylvania of 1979. ${ }^{10}$

During a fifteen-year period, support developed to amend Pennsylvania law to permit the development of direct relationships between the state library and academic libraries. With support from both the academic library community and the state library, this change was accomplished in 1981 when the State Librarian was given statutory authority to "promote and support cooperation among the various types of libraries in Pennsylvania for the purpose of increasing the services and resources through libraries." ${ }^{11}$ In 1982-83, academic libraries participated fully in developing a comprehensive plan of library development. ${ }^{12}$ When Access Pennsylvania, the state library's current long-range plan, was implemented, the role of academic libraries had developed to the point that a Resource Sharing and Academic Libraries Section was created within the state library to carry out initiatives related to academic libraries. ${ }^{13}$ By 1986 , resource sharing was well under way and a fuller understanding of the specific concerns of academic libraries was appropriate. To that end, the proposal for this study was approved.

\section{OBJECTIVES AND METHODOLOGY}

This study is intended to assess academic library needs that can be addressed by the State Library of Pennsylvania's Office of Resource Sharing and Academic Libraries. The study has three objectives:

1. to identify high-priority needs among Pennsylvania academic libraries.

2 . to differentiate between those highpriority needs that are being addressed satisfactorily and those that are not.

3 . to collect recommendations from academic librarians on how the state library might best meet high-priority needs that are not being satisfactorily addressed.

A two-phase research methodology was employed. The first phase was built around a population survey of Pennsylva- nia academic libraries to collect data on needs and satisfaction. The survey addressed the first two objectives by identifying loosely defined areas of need and satisfaction. The second phase used focus groups, composed of librarians representing a range of academic libraries, to define and interpret the results of the survey and to recommend appropriate action for the state library. From a methodological point of view, the two-phase research design was useful because it provided an accuracy check on the survey data and focused group discussions on topics where unmet needs are highest and programs are most likely to be developed. The following paragraphs discuss the methodology and response in more detail.

A survey questionnaire was developed to collect information about three broad areas of services supporting academic libraries that the state library considered appropriate to develop or enhance. In the first section libraries were asked to indicate their need for, use of, and satisfaction with eleven activities related to access and resource sharing. In the second section respondents were asked to identify their need for, use of, and satisfaction with eleven technical assistance services related to local library operations. In the third section libraries were asked to indicate the importance of, the extent to which the library addresses, and satisfaction with eleven general environmental issues affecting academic libraries. The body of the questionnaire is provided in appendix A. ${ }^{14}$

Respondents were also asked to identify their highest priority needs overall and within each section of the questionnaire. Open-ended questions were provided in each of these sections to encourage unique responses. The questionnaire concluded with three demographic questions on networking and automation that could not be answered with available NCES data. ${ }^{15}$

The questionnaire was developed in consultation with state library personnel and pretested in four academic libraries in Maryland. The final draft was reviewed with members of the Pennsylvania Council of Library Networks, an organization composed of representatives from library 
networks and academic library consortia within the commonwealth. The questionnaire was mailed to directors of the population of 180 libraries at Pennsylvania postsecondary institutions offering at least a two-year degree. A cover letter was included requesting a response by December 1986. No follow-up mailings were made, but responses were accepted through January 1987.

Usable responses were received from directors representing eighty-two libraries or 45.5 percent of the population. Two sample chi-square analyses indicated no significant difference at the .01 level between responding libraries and the population of libraries on four key demographic variables: Carnegie classification; HEGIS classification; public or private support; or number of volumes (see table 1). It is assumed that responses reflect the needs and satisfaction levels of Pennsylvania academic libraries.

Responses were analyzed using the SPSSx statistical package. ${ }^{16}$ Open-ended questions were coded and analyzed. Marginal data for need or importance, use of address, and for satisfaction are presented in the appendix. Statistical analysis was limited to percentages and chi-squares to facilitate understanding and encourage discussion in the focus groups.

The second phase of the research was built around meetings with four focus groups selected for their ability to represent important facets of the Pennsylvania academic library community: Associated College Libraries of Central Pennsylvania; Council of Pennsylvania Library Networks; Pennsylvania Community College Libraries Council; and State System of Higher Education Library Council. ${ }^{17}$ Each focus group meeting began with a review of the priorities and satisfaction levels developed from the survey data. Since most of the participants had completed a questionnaire and were familiar with the study, the review quickly summarized the study goals and procedures and emphasized presenting the analyzed data.

Focus group participants were then guided through a discussion of the data emphasizing three areas of questions. How does this information compare with your understanding of the needs and satisfaction levels of academic libraries in Pennsylvania? What are the concerns involved in addressing these needs? What specific activities might the state library provide that would address these needs effectively? Focus group discussions were collected and assessed. They form an integral part of the analyses and recommendations in this report.

\section{PRIORITIES}

At the end of the survey questionnaire, respondents were asked to rank their library's five most critical needs in priority order. Responses indicated academic library priorities for services that might be developed or enhanced by the State Library of Pennsylvania's Office of Resource Sharing and Academic Libraries. A value voting technique was used to rank these responses. Each respondent's highest priority was assigned a value of five, the second highest priority a value of four, and so forth through the five needs listed. Values assigned for each need by all respondents were then summed to arrive at overall need priorities. Specific questionnaire wording, number of respondents (R), percentage of respondents indicating they already use services or address issues (Address \%) and mean satisfaction levels (Satis $\bar{X}$ ) are provided for each priority (Priority) in the appendix. Recognizing the limited time available for focus groups to review the priorities and to suggest ser-

TABLE 1

TESTS FOR DIFFERENCES BETWEEN POPULATION AND RESPONDENTS

\begin{tabular}{lccc}
\hline \hline Variable & Chi-square Observed & Chi-square .01 & df \\
\hline Carnegie classification & 9.477 & 13.277 & 4 \\
HEGIS classification & 14.844 & 15.086 & 5 \\
Public/private & .476 & 6.634 & 1 \\
Number of volumes & 9.823 & 13.277 & 4 \\
\hline
\end{tabular}


vice alternatives, it was decided to limit analysis of priorities to the thirteen of thirty-three needs or issues with the highest value scores.

Needs are listed in priority order (Pri\#) in table 2. The summed valued scores (Val) are provided to indicate the relative level of need for each priority. Respondents indicate three distinct value score plateaus for high-need priorities. New technology (e.g., CD-ROM, laser disks, micros, etc.) and development of machine readable bibliographic databases including retrospective conversion are the highest needs of Pennsylvania academic libraries. Many respondents list these two needs as their first or second priority. The six needs beginning with union lists (e.g., statewide or regional catalogs, serials lists, manual or automated) and ending with personnel development and status form a second plateau of high-priority scores. Many respondents list these needs among their top five priorities, and some respondents indicate they are their highest priorities. The last five needs form a third plateau. Respondents regularly listed them among their top five priority needs.

Also of interest is identifying the broad areas of concern (ASI) from which specific high-need priorities were drawn: access and sharing of resources (A); provision of library services (S); and issues affecting academic libraries (I). Table 2 clearly indicates that Pennsylvania academic libraries are not seeking state library technical assistance or guidance in the direct provision of local academic library services.
Only two provision-related needs-access to bibliographic information and cooperative technical services-appear in the high-need priorities, and they are near the bottom. Instead, the data indicate that Pennsylvania academic libraries are seeking assistance on access and issues-related needs.

Taken as a whole table 2 indicates that focus groups might profitably discuss four general areas of need. New technologies, broadly defined as including CD-ROM, microcomputers, and other equipment; machine readable databases; retrospective conversion and other applications, form the highest priorities. Traditional cooperative activities, including union lists, reciprocal borrowing, cooperation with other types, and cooperative technical services, form a second area of need. Infrastructure concerns, including interlibrary loan, communication networks, telecommunications, linked system protocols, and access to bibliographic information, form a third set of needs. The three remaining needs, advocacy, personnel development, and preservation, can not be grouped under a convenient label and are considered separately.

\section{UNSATISFIED NEED PRIORITIES}

To determine which high-need priorities are already being satisfactorily addressed, responding academic libraries were asked to indicate the extent to which they already use services or address issues in each priority and their satisfaction with

TABLE 2

HIGH-NEED PRIORITIES

\begin{tabular}{lcccr}
\hline \hline Need Priority & Prif & Val & ASI & Q \\
\hline New technology & 1 & 128 & I & 30 \\
Machine-readable bibliographic databases & 2 & 104 & A & 10 \\
Union lists & 3 & 78 & A & 1 \\
Reciprocal borrowing & 4 & 75 & 7 & 4 \\
Cooperative relations with other types & 5 & 70 & I & 31 \\
ILL communication networks & 6 & 69 & I & 28 \\
Advocacy of academic library needs & 7 & I & 26 \\
Personnel development and status & 8 & 97 & 32 \\
Telecommunications & 10 & 49 & I & 29 \\
Linked online system protocols & 11 & 48 & 25 \\
Access to bibliographic information & 12 & 42 & A & 14 \\
Preservation of library materials & 13 & 41 & S & 2 \\
Cooperative technical services & & & 12 \\
\hline
\end{tabular}


their efforts. Table 3 lists high-need priorities in ascending order of mean satisfaction (Satis $\bar{X}$ ), measured using a five-point Likert scale. The percentage of libraries who are addressing the priority (Address\%) and the number of libraries responding $(\mathrm{R})$ on each priority are also provided.

For the purposes of this study, mean satisfaction levels of less than three (3.00) on a five-point Likert scale are assumed to identify high-need priorities that are not currently being satisfactorily addressed in Pennsylvania academic libraries. The first four priorities in table 3 report mean satisfaction levels of less than three, indicating high-priority needs that are not being satisfactorily addressed. Pennsylvania academic libraries are not satisfied with their efforts to address advocacy of academic library needs in state government, linked online system protocols, telecommunications (e.g., fiber optics, wired campus, microwave, etc.), or new technology (e.g., CD-ROM, laser disks, micros, etc.).

Mean values between three (3.00) and four (4.00) on a five-point Likert scale are assumed to identify high-need priorities that are being satisfactorily treated or addressed but that are open for further improvement. Priorities listed between personnel development and access to bibliographic information are need priorities where Pennsylvania academic libraries report reasonable satisfaction with current efforts, but which they think might be improved to good effect.
Mean values above four (4.00) on a fivepoint Likert scale are being addressed most satisfactorily. Reciprocal borrowing is operating very well among Pennsylvania academic libraries.

A second observation is the positive correlation between the percentage of libraries using a service or addressing an issue priority need (Address\%) and the satisfaction with the area of need (Satis $\bar{X}$ ). Pennsylvania academic libraries seem to be reasonably satisfied with what they are doing, but would appreciate assistance from the state library on several priorities they have not yet been able to address.

\section{FOCUS GROUP RECOMMENDATIONS}

High-need priorities and unsatisfied need priorities were shared with four focus groups, each composed principally of academic library directors, to develop recommendations on how the Office of $\mathrm{Re}$ source Sharing and Academic Libraries should address the needs of academic libraries in Pennsylvania. The four focus groups were: the Associated College Libraries of Central Pennsylvania; the Community College Library Consortium; the Council of Pennsylvania Library Networks; and the State System of Higher Education Library Council. Each of these groups could make a valuable and unique contribution in interpreting the survey results and recommending appropriate action for the state library.

Each focus group meeting began with a

TABLE 3

UNSATISFIED NEED PRIORITIES

\begin{tabular}{llcc}
\hline \hline Need Priority & Satis $\bar{x}$ & Address\% & R \\
\hline Advocacy of academic library needs & 2.00 & 16.9 & 65 \\
Linked system protocols & 2.64 & 17.0 & 53 \\
Telecommunications & 2.64 & 32.8 & 58 \\
New technology & 2.90 & 43.8 & 80 \\
Personnel development & 3.11 & 62.2 & 65 \\
Preservation of library materials & 3.16 & 30.5 & 59 \\
ILL communication networks & 3.35 & 68.9 & 73 \\
Machine-readable databases and & 3.65 & 48.5 & 66 \\
retrocon & 3.72 & 100.0 & 78 \\
Union lists and catalogs & 3.83 & 80.3 & 76 \\
Cooperation with other types of libraries & 3.97 & 58.0 & 50 \\
Cooperative technical services & 3.97 & 93.8 & 64 \\
Access to bibliographic information & 4.09 & 91.5 & 82 \\
Reciprocal borrowing & & &
\end{tabular}


"Small libraries, for example, were more likely to be interested in direct consultation services, while larger libraries with research and historical collections expressed very high interest in preservation."

review of the needs priorities (see table 2) and unsatisfied needs (see table 3). Participants discussed the information and, in general, confirmed that it reflected their understanding of academic libraries in Pennsylvania. In discussing need priorities, each focus group noted distinctions in interpreting needs data on the basis of size of library and institutional goals. Small libraries, for example, were more likely to be interested in direct consultation services, while larger libraries with research and historical collections expressed very high interest in preservation. The focus groups also pointed out that some needs might best be met by involving other types of libraries to a greater or lesser extent. The following paragraphs summarize comments on the first four unsatisfied needs and for preservation, each of which were considered appropriate and desirable areas for the state library to develop or enhance services. ${ }^{18}$

Advocacy of academic library needs within state government is considered to be a broad priority that can be addressed in a number of ways. Within the state library agency, focus groups recommend that the office advocate issues and programs that will benefit academic libraries, such as the interlibrary loan compensation plan proposed in Access Pennsylvania. ${ }^{19}$ In other agencies of state government, the office can encourage links with academic libraries through grants and contracts. Concurrently, the office should improve academic library understanding of state government through continuing education on the political and funding processes. The office can also serve an important function by advocating academic libraries and their campus and community roles to chief executive officers and chief academic officers through state govern- ment channels and forums. The advocacy of academic libraries should be based on consultative leadership and a strong program of communication between the office, academic libraries, and interlibrary organizations.

Focus groups indicated the office should take a leadership role in working among libraries and networks to develop and implement linked system protocols. Two forms of linking are currently perceived as important. Links among bibliographic utilities, integrated library systems, and gateways will permit enhanced services between libraries. Second, improved ability to link in-house stand-alone library automation systems will result in virtual integrated library systems within academic libraries. Addressing the first part of the need will involve other types of libraries and will be guided by Access Pennsylvania programs of reciprocal borrowing, interlibrary loan compensation, and the statewide union catalog. Addressing individual library needs will be based on evaluation of stand-alone systems, particularly their ability to connect with each other locally and their compatibility with statewide services and criteria.

Telecommunications development for Pennsylvania libraries of all types should be focused in the Office of Resource Sharing and Academic Libraries. The office has already undertaken a study of Pennsylvania telecommunications that is considered a model. New developments in fiber optics, microwave, and cable should continue to be assessed for their ability to meet library needs for voice and data grade communications throughout the commonwealth. The office should plan and help initiate new communication patterns among libraries when appropriate.

Academic libraries would like access to objective information and evaluations of new technology for libraries. They believe this is an appropriate consultative service for the state library agency in that it has an interest in being able to link libraries for resource sharing as well as general library welfare. Academic libraries would like information on both hardware and software for library automation, integrated library systems, and gateways to information in 
electronic formats, as well as the telecommunications and linked system protocols previously mentioned.

Academic libraries with research and historical collections and libraries that make use of these collections want the office to undertake a leadership position in preservation. These collections range from nonprint materials in junior colleges to manuscripts and unique holdings in college library special collections and the collections of the major research libraries. Focus group participants first want the office to arrange access to preservation facilities, either by guiding the development of cooperative efforts or by contracting with existing operations. Second, academic libraries want consultative assistance to determine what they should do locally to preserve their collections. They believe the office is an excellent locus for preservation activity throughout the commonwealth.

Finally, focus groups indicate that efforts to implement linked system protocols, telecommunications, and new technologies should be closely coordinated with existing networks and consortia operating in the commonwealth. Efforts to improve bibliographic services, for example, should consider the role of Palinet and PRLC, the regional vendors of OCLC services, as well as the Research Libraries Group and the state library's own CDROM union catalog. Similarly, efforts to enhance telecommunications should consider using both commercial and dedicated networks such as those operated by Bell, state government, educational institutions, and bibliographic utilities. Throughout, the state library should maintain a good neighbor policy, encouraging local and regional solutions while setting broad goals and criteria that will facilitate statewide resource sharing and cooperation.

\section{SUMMARY}

The purpose of this study has been to identify needs of Pennsylvania academic libraries that can be addressed by the state library's Office of Resource Sharing and Academic Libraries. The questionnaire gathered information on need priorities and levels of satisfaction. The use of focus groups provided guidance to the office on how it might best address unsatisfied, high-priority needs while at the same time building consensus in the academic library community supporting state library actions.

Results of this research suggest that the state library support academic libraries by developing programs and activities that address five high-need priorities that also report high unsatisfied need. Advocacy can be addressed in several ways, in the state library, in other offices of state government, and from state government to academic administrators. The office should continue its pioneering telecommunications efforts and extend them to include the fostering of linked system protocols. The office should develop a consultative role in new technology that would encourage rational implementation of new technologies in the academic library community. Finally, the office should coordinate the development of and access to preservation facilities and should provide guidance for local library preservation activities.

By undertaking these activities the State Library of Pennsylvania will build stronger relationships with academic libraries throughout the commonwealth. As a consequence the state library agency will be better able to coordinate overall library development, especially for those services that depend upon resource sharing among libraries of all types. By using state library services, academic libraries stand to gain assistance on a range of needs that they consider important but undersupported. Carefully designed and implemented initiatives should result in synergistic solutions for issues of concern to both academic libraries and the State Library of Pennsylvania.

The findings of this study may also be helpful to other academic libraries and state library agencies as they work to improve resource sharing and library cooperation. The methodology could be successfully replicated in other states to identify academic library needs that can be appropriately addressed by the state library agency and to build consensus in the 
academic library community for such activity. While it is methodologically incorrect to generalize the findings of this population survey or the recommendations of the focus groups, the needs priorities discussed here my be applicable in other states to the extent they are similar to the academic library community in Pennsylvania. Certainly, the results of this study can be used to initiate similar efforts intended to strengthen relationships between academic libraries and state library agencies.

\section{REFERENCES AND NOTES}

1. Phillip Monypenny, The Library Functions of the States (Chicago: American Library Assn., 1966); Dorothy A. Kittel, Trends in State Library Cooperation (Washington, D.C.: Govt. Print. Off., 1975).

2. David C. Weber, "A Century of Cooperative Programs among Academic Libraries," College \& Research Libraries 37: 205-21 (May 1976).

3. Robert F. Moran, "Library Cooperation and Change," College \& Research Libraries 39:268-74 July 1978); Beverly P. Lynch, "The Changing Environment of Academic Libraries," College \& Research Libraries 39:10-14 (Jan. 1978).

4. Barbara E. Markuson, "Cooperation and Library Network Development," in New Horizons for Academic Libraries (New York: Saur Verlag, 1979), p. 30-42; Patricia Battin, "Research Libraries in the Network Environment," Journal of Academic Librarianship 6:68-73 (May 1980); William J. Baumol and S. A. Blackman, "Electronics, the Cost Disease, and the Operation of Libraries," Journal of the American Society for Information Science 34:181-91 (Mar. 1981).

5. James S. Healey, "Public-Academic Library Cooperation," College \& Research Libraries 32:121-26 (Mar. 1971).

6. Applied Management Sciences, A Study of Library Cooperatives, Networks and Demonstration Projects, 2v. (Silver Spring, Md.: Applied Management Sciences, 1978).

7. Nancy L. Wareham, ed., The Report on Library Cooperation, 6th ed. (Chicago: Assn. of Specialized and Cooperative Library Agencies, 1986).

8. Thornton W. Mitchell, The State Library and Library Development in North Carolina (Raleigh, N.C.: North Carolina Department of Cultural Resources, 1983); New Jersey State Library, A Developing State Plan for Library Services (Trenton, N.J.: Department of Education, 1980); Beth Givens, Pilot Moncat: Making Way for Montana's Union Catalog (Helena, Mont.: Montana State Library, 1985).

9. Drexel University, Graduate School of Library Science, Directory of Pennsylvania Library Resources, 2d ed. (Philadelphia: Graduate School of Library Science, 1972).

10. Pennsylvania Library Master Plan Committee Report (Harrisburg: State Library of Pennsylvania, 1974); State Library of Pennsylvania, Bibliographic Access in Pennsylvania (Harrisburg: State Library of Pennsylvania, 1979).

11. Pennsylvania Consolidated Statutes, Title 71, Sec. 1031, (1981).

12. State Library of Pennsylvania, Comprehensive Plan for Library Service in Pennsylvania (Harrisburg: State Library of Pennsylvania, 1983).

13. State Library of Pennsylvania, Access Pennsylvania (Harrisburg: State Library of Pennsylvania, 1984).

14. Copies of the complete questionnaire and supporting data are available from Charles $\mathrm{T}$. Townley, Heindel Library, The Pennsylvania State University at Harrisburg, Middletown, PA 17057.

15. National Center for Educational Statistics, Library Statistics of Colleges and Universities: 1982 Institutional Data (Chicago: Assn. of College and Research Libraries, 1984).

16. SPSSx User's Guide (New York: McGraw-Hill, 1986), p.314-53.

17. Toni H. Lydecker, "Focus Group Dynamics," Association Management 38:73-78 (Mar. 1986); Sumru Erkut and Jacqueline P. Fields, "Focus Groups to the Rescue," Training and Development Journal 41:74-76 (Oct. 1987).

18. Charles T. Townley, "Developing Relationships between Academic Libraries and the State Library of Pennsylvania: A Report of Research with Recommendations," Middletown, Pa., 1987 (mimeographed).

19. State Library, Access Pennsylvania. 


\section{APPENDIX A. QUESTIONNAIRE AND MARGINAL DATA}

\section{Access and Sharing of Resources}

Listed below are activities for which the state library Office of Resource Sharing and Academic Libraries might encourage to improve access and sharing of resources.

\section{Please Check:}

A. Those activities that your library currently needs or anticipates needing this fiscal year.

B. Those activities that your library currently uses.

C. On a scale of 1 to 5 , with 1 representing low satisfaction and 5 representing high satisfaction, indicate your library's satisfaction with the activities your library currently uses.

A. Need

\section{Priority}

1. Union lists (e.g., statewide or regional catalogs, serials lists, manual or automated).

2. Preservation of library materials (e.g., deacidification, microform, last copy storage, etc.).

3. Cooperative collection development

4. Reciprocal borrowing agreements

5. Evaluation of automated library systems (e.g., circulation, catalog, acquisitions, ILL, etc.).

6. Evaluation of equipment (e.g., furniture, library equipment, microcomputers, etc.).

7. Cooperative purchasing (e.g., materials, supplies, equipment, systems, etc.)

8. Cooperative collections of nonprint materials (e.g., film, microcomputer software, etc.).

9. Cooperative contracting for services (e.g., online databases, service contracts, etc.).

10. Development of machine readable bibliographic databases and retrospective conversion.

11. Other:
82
B.

Use

(Address\%)

100.0

30.5

24.1

91.5

31.9

37.7

50.9

43.5

56.5

48.5

NA
Satis.

(Satis $\bar{X}$ )

4.09

3.39

\section{5}

NA

\section{Priority 1}

Now select up to three (3) access and resource sharing activities (numbers 1-11) that represent your greatest needs, whether or not you currently use them. Rank them in priority order, from 1 to 3 with 1 as the highest priority. List only the number (1-11).
1.
2.
3.

\section{Provision of Library Services}

Listed below are examples of technical assistance that might help you in the operation of your library.

Please Check:

A. Those services which your library currently needs or anticipates needing this fiscal year.

B. Those services your library currently uses.

C. On a scale of 1 to 5 , with 1 representing low satisfaction and 5 representing high satisfaction, indicate your library's satisfaction with services your library currently uses.

A.

Need

50
B.

Use

C.

Satis.

\section{Priority}

12. Cooperative technical services (e.g., joint acquisitions, cataloging, periodicals, etc.).
(Address\%)

58.0
(Satis $\bar{X}$ )

4.13 
13. Guidance in technical services (e.g., consult- 47 ing).

14. Access to bibliographic information (e.g., 64 MARC, NUC, etc.). 15. Cooperative reference services (e.g., reference
referral, joint online searching, etc.).

16. Guidance in reference services (e.g., consult- 40 ing).

17. Cooperative access services (e.g., shared circulation, reserve, etc.).

18. Guidance in access services (e.g., consulting).

19. Guidance in administrative services (e.g., consulting).

20. Guidance in facility design and development (e.g., consulting).

21. Clearinghouse (e.g., exemplary models, policies, consultant lists, etc.).

22. Other:

\section{Priority 2}

Now select up to three library services (Numbers 12-22) which represent your greatest needs, whether or not you currently use them. Rank in priority order, from 1 to 3 with 1 as the highest priority. List only the number (12-22).

$$
1 .
$$

3.

\section{Issues Affecting Academic Libraries}

Listed below are some general issues affecting academic libraries that might be addressed by the State Library Office of Resource Sharing and Academic Libraries.

Please Check:

A. Those issues which are important to your library or which you expect to be important to your library this fiscal year.

B. Those issues which your library currently addresses.

C. On a scale of 1 to 5 , with 1 representing low satisfaction and 5 representing high satisfaction with your library's efforts to address each issue.

\section{Priority} Impt.

23. Intellectual freedom

24. Electronic information (e.g., statistical datafiles, digitized test, etc.).

25. Linked online system protocols

26. Advocacy of academic library needs

27. Institutional contracting for library services (e.g., new federal policy).

28. Interlibrary loan communication (e.g., IDS, electronic bulletin boards, telefacsimile, etc.).

29. Telecommunications (e.g., fiber optics, wired campus, microwave, etc.).

30. New technology (e.g., CD-ROM, laser disks, 80 micros, etc.).

31. Cooperative relations with other types of libraries.

32. Library personnel development and status.

33. Other:
A.

B.

C. Address

\section{(Address\%)}

68.5

43.5 Satis.

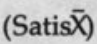




\section{Priority 3}

Now select up to three issues (numbers 23-33) that are most important to your library, whether or not you currently address them. Rank in priority order from 1 to 3 with 1 as the highest priority. List only the number (23-33).

1.

2.

3.

\section{Composite Priority Ranking}

Priority 4

To further refine the specific needs of your library, please select up to five (5) items that you consider to be your highest needs, whether or not they are currently addressed. Rank them from 1 to 5 with 1 as the highest priority. List only the number (1-33).

1.

2.
3.

4.

5.

\section{BA/RRM HAS IT ALL! Over 1600 meetings, plus patents, books and more!}

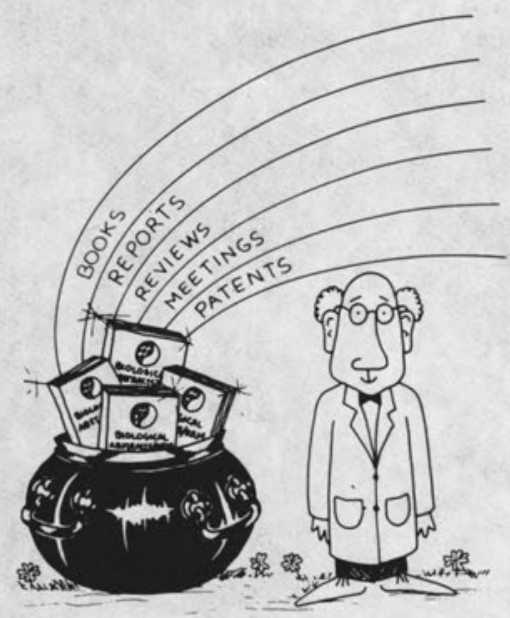

With Biological Abstracts/RRM * (Reports, Reviews, Meetings) you'll receive 260,000 entries for 1988 from over 9,000 serials and other publications from over 100 countries.

No other reference publication provides you with comprehensive coverage of symposia papers, meeting abstracts, review publications, bibliographies, research communications, books, book chapters and U.S. patents. In three easy-to-use sections-Content Summaries, Books and Meetings.

The indexes in each issue provide four modes of access to the literature: Author, Biosystematic, Generic and Subject.

Take advantage of this excellent coverage of important new scientific research and discoveries for your library.

Make sure your library has it all! Subscribe today by contacting BIOSIS Customer Services, 2100 Arch Street, Philadelphia, PA 19103-1399 USA Telephone toll free 1-800-523-4806 (USA except PA) or (215) $587-4800$ worldwide. Telex 831739; Fax (215) 587-2016. Or contact the Official Representative in your area.

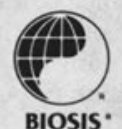




\section{ACQUISITION PERSPECTIVES}

6. Book House is in its fourth generation of automation. Our custom software allows us the flexibility to accept orders generated through your computerized system or in the mail. Our policy is to develop a working compatibility with the automated system in your library to facilitate receiving orders, transmitting open order reports and invoices electronically.

Let's explore interfacing your automation with ours.

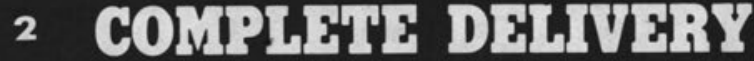

\section{RUTOMETON}

HBRERY - VNNDOR IVIX:FECE

BOOK HOUSE

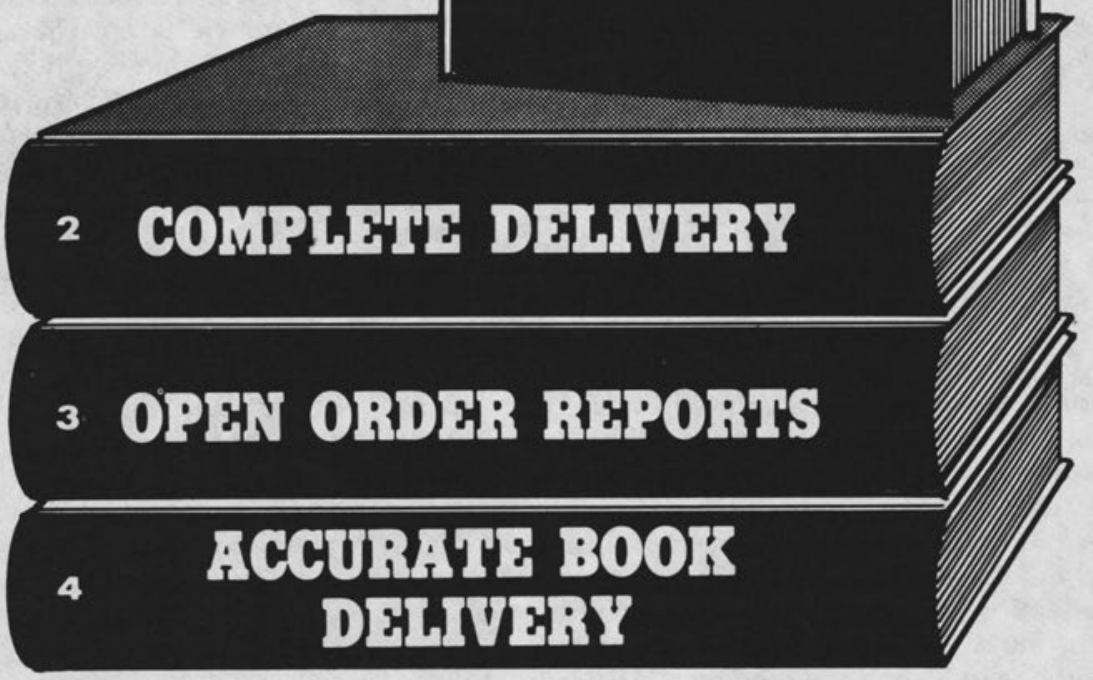

CALL TOLL-FREE TODAY

1-800-248-1146

In Canada \& Michigan

CALL COLLECT (517) 849-2117

OCLC Vendor No. 17397

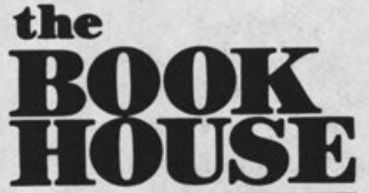

JOBBERS SERVING LIBRARIES WITH ANY BOOK IN PRINT SINCE 1962 208 WEST CHICAGO STREET JONESVILLE, MICHIGAN 49250 